\title{
Revisiting weed infestation of agricultural lands from zones near utility poles
}

\author{
Kirill Zhichkin ${ }^{1}$, Vladimir Nosov ${ }^{2,3,{ }^{*}, \text { Lyudmila Zhichkina }}{ }^{1}$, Yury Shlenov ${ }^{2}$, Yulia \\ Melnikova $^{2}$, and Halin Aydinov ${ }^{2}$ \\ ${ }^{1}$ Samara State Agrarian University, 2, Uchebnaya str., 446442, Kinel, Russia \\ ${ }^{2}$ K.G. Razumovsky Moscow State University of Technologies and Management, 73, Zemlyanoy val, \\ 109004, Moscow, Russia \\ ${ }^{3}$ Academy of the Investigative Committee of the Russian Federation, 12, Vrubel Str., 125080, \\ Moscow, Russia
}

\begin{abstract}
Field research of land lots over a 4865 ha area has demonstrated that the main sources of agricultural lands infestation are raw pieces of land (inarable lands), wood lines, dirt roads or indigested manure, used as organic fertilizer. The specific weight of weeds patches around the power line support is less than $0.013 \%$ of all weeds sources, suggesting that there is a minimum damage to agricultural crops, compared to other sources of weeds distribution in the given area. The authors of the paper propose to use chemical treatment with non-selective herbicides as the most effective measure of weeds control around the utility poles, at a cost, according to the results of the research, of $0.21 \mathrm{rub} / \mathrm{ha}$. As a result, the issue of compensation payments to agricultural producers from energy companies should be defined by the cost value of chemical treatment of agricultural lands in zones near utility poles.
\end{abstract}

\section{Introduction}

In conducting field works in the power lines zones, the question of compensation payments to landowners and land users from energy companies is often raised. The main rationale for these payments is the assertion that there are limited possibilities for cultivation of soil around utility poles constructed for power lines support, which results in weeds centers [1]. As a result, the general background of agricultural lands infestation increases and leads to reduction in yields and escalation of weed control costs [2, 3, 4].

The purpose of the research is to determine the impact of distribution of weeds from zones near the utility poles on the general background of agricultural lands infestation and the amount of compensation payments to land users. The following objectives were addressed in the research: examination of weeds spots sizes and weeds composition in zones near the utility poles; identification of possible weeds sources in the studied territory; determination of impact of each infestation source on the general background; definition of the role of zones near the utility poles as the source of infestation; development of

* Corresponding author: novla@list.ru 
agrotechnical measures for power lines management in order to reduce their negative impact on lands.

\section{Methods and materials}

A site survey of land plots with cadastral numbers $63: 14: 0802002: 65 ; 63: 14: 0803002: 10$; 63:14:0802002:66; 63:14:0803002:3 and surrounding areas was conducted with the use of satellite monitoring [5, 6]. The results are presented in Figure 1, Figure 2 and Figure 3.

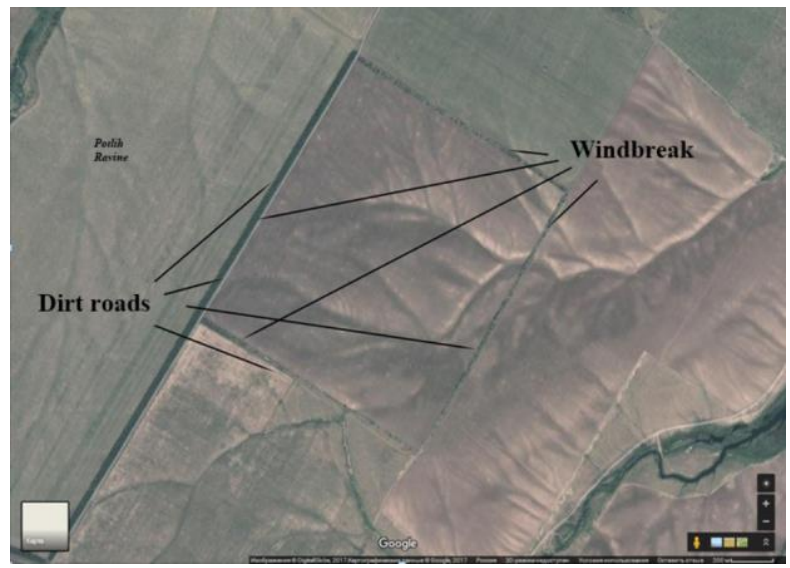

Fig. 1. Satellite photo of land plots with cadastral numbers 63:14:0802002:65 and 63:14:0802002:66. Acquired by authors using Google Maps.

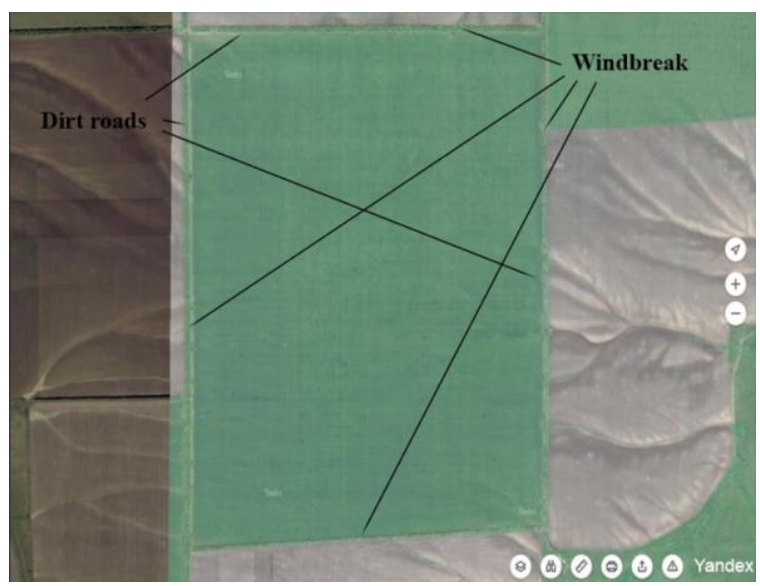

Fig. 2. Satellite photo of the land plot with cadastral number 63:14:0803002:10. Acquired by authors using Yandex.Maps.

These land plots constitute a territory of the shape of an almost regular quadrangle, bounded by windbreaks 12-15 meters wide on all sides. Dirt roads are located along the perimeter of the field. A 'Maiskaya' $35 \mathrm{~kW}$ power line runs though all described plots, where poles with numbers \#26-34, \#81-109 are located. The poles are cylindrical with a diameter of $500 \mathrm{~mm}$ at the base.

In accordance with agrobiological classification [7], annual and perennial nonparasitic weeds were found around utility poles [8]. Annual weeds are characterized by seed reproduction, life cycle of no more than 2 years, and die right after seeds develop. Perennial 
weeds grow for a few years, can bear multiple times during their life cycle, and reproduce by seeds and vegetatively.

Such annual plants as common wild oat, white goosefoot, mayweed, pearl milllet, etc., and perennial plants as Canada thistle, field milk thistle, absinthe, spurge, etc. were found on examined plots.

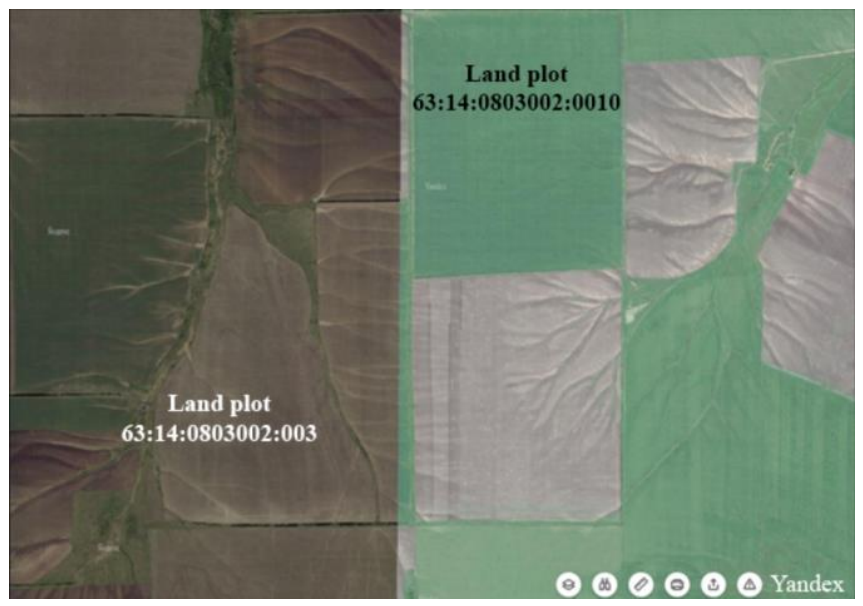

Fig. 3. Satellite photo of land plots with cadastral numbers 63:14:0803002:10 and 63:14:0803002:003. Acquired by authors using Yandex.Maps.

Figure 4 shows an uncultivated spot, overgrown with weeds, is an irregular circle with a diameter of 4-5 diameters of poles.

Accordingly, the area of one spot is about $4 \mathrm{~m}^{2}$. Therefore, the total area of all spots (36 poles) is $144 \mathrm{~m}^{2}$. The spot of land around the $\# 81$ pole should also be considered, as the area of weeds is larger there (because of cable stays) $-12 \mathrm{~m}^{2}$. The total area of weeds around utility poles is about $156 \mathrm{~m}^{2}$.

\section{Results and discussion}

The results of examination show that fields and the territory around them are prone to wind and water erosion, as evidenced by the existence of ravines, the area of which is set aside. To a large extent, it can be seen on the land plot with a cadastral number 63:14:0803002:003, divided into 2 parts by the ravine (in the \#99-100 poles midspan). In this case ravines and other uncultivated land spots are the main sources of weeds distribution. 


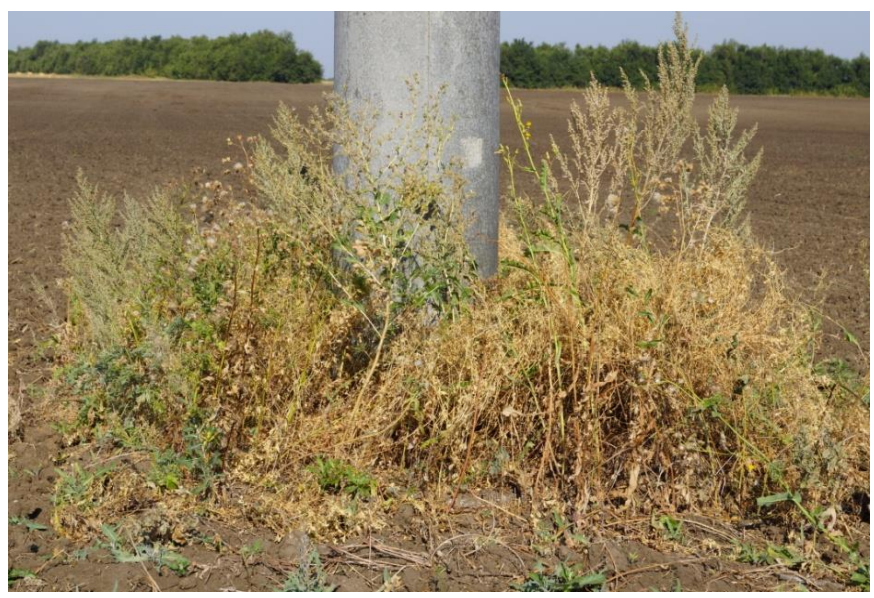

Fig. 4. The size of the spot overgrown with weeds.

Windbreaks and dirt roads along the field perimeter are another source of infestation [9]. The role of windbreaks in defense against the weeds seeds dispersion can hardly be overestimated. They hold up almost $100 \%$ of seeds dispersed by wind. However, they subsequently serve as a source of weeds distribution.

According to Figure 5, the third source of seeds dispersion on these plots is fresh manure, that was found on examined fields. Even if manure is decomposed into indiscrete mass with no separate straws, some of weeds seeds are still viable. In this case it is more an issue of fresh or almost decomposed manure. In accordance with research conducted in the Saratov region, $10 \mathrm{t} / \mathrm{ha}$ of applied manure, results in $0.8-1.0 \mathrm{mln}$. weeds seeds, which is only 4-5 times less than the seeding rate for winter wheat, for example (4.0-5.0 mln./ha) [10].

Another infestation factor is weeds spots around utility poles. Vegetative primordials in the soil cannot cause fast dissemination over large areas. Roots and rootstock running riot cause gradual spread of suckering and rootstock weeds. The area occupation happens very slowly in this case. For example, clumps of sow thistle, found on examined land plots, increase only 2-3 meters in diameter in a year of root spreading.

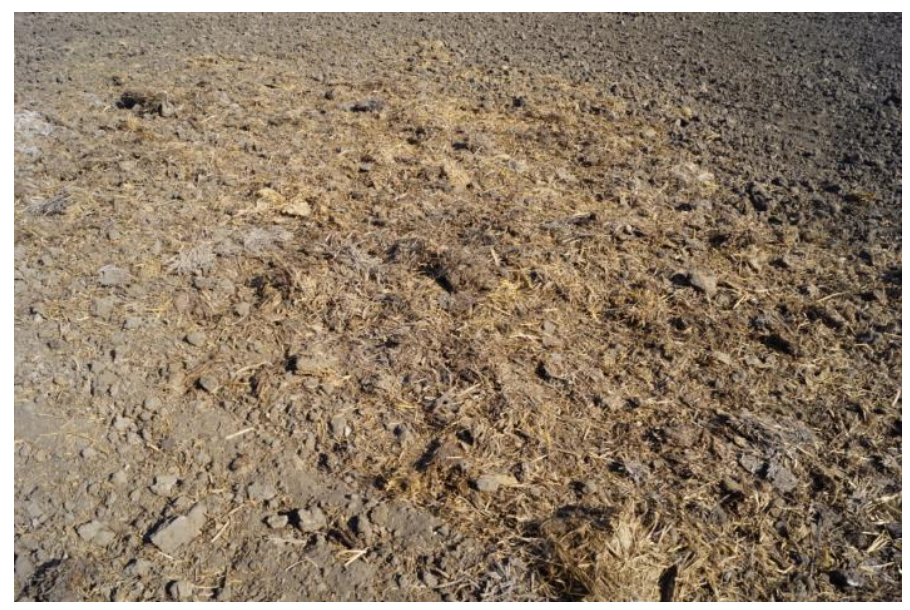

Fig. 5. Manure applied on examined land plots (63:14:0803002:0010).

In order to disperse by wind, some weeds have pappuses or wings, others fly due to small sizes and light seeds, and still others form large spherical bushes - tumbleweed. The 
most wide-spread and dangerous annual weeds with pappuses are lettuce, horseweed and goatsbeard, and among soboliferous - sow thistle and blue lettuce. Weeds such as dandelion, narrowleaf hawksbeard, cottonthistle, ragworts, etc. are less harmful.

Seeds with pappuses fly into the air especially easily during harvesting using the reaping machine. Seeds can levitate in the air for a long time and can be transported over long distances ( 3 kilometers and more). In windy weather they do not come down for a long time. If the weather is changeable, the wind carries them by bounds.

In order for seeds with pappuses to land, special conditions are required: they do not stay on bare soil, rarely settle in stubble, more frequently - in plantings. Cultivated plants herbage protects them from being carried away by the wind before embedding. Seeds with pappuses stay put on the woodland edge and within windbreaks even in windy weather.

It is rather difficult to compare the roles of all weeds seeds sources.

The first source (ravines, inarable lands and other uncultivated plots) can be characterized in accordance with the following examples. On the boundary of the 63:14:0802002:66 land plot and a field (not marked on a public cadastral map), between poles \#34-36, there is an uncultivated plot of 20 ha, overgrown with weeds. The second example is a ravine that divides the 63:14:0803002:003 land plot into 2 sections (poles \#99100). Within the land plot its width varies from $10 \mathrm{~m}$ to $700 \mathrm{~m}$ with the length being 2.3 $\mathrm{km}$. Accordingly, the approximate area overgrown with weeds is no more than 50 ha, without taking into account other plots.

The second source is windbreaks and dirt roads. All four land plots are surrounded by a perimeter of windbreaks, as can be seen from Table 1.

Table 1. Area of windbreaks and dirt roads around examined land plots.

\begin{tabular}{|c|c|c|c|c|c|}
\hline \# & $\begin{array}{c}\text { Cadastral number of a } \\
\text { land plot }\end{array}$ & Object & Length, $\mathbf{m}$ & Width, m & Area, ha \\
\hline 1 & $\begin{array}{c}63: 14: 0802002: 65 ; \\
63: 14: 0802002: 66\end{array}$ & Windbreak & 5720 & 15 & 8.6 \\
\hline 2 & $\begin{array}{c}63: 14: 0802002: 65 ; \\
63: 14: 0802002: 66\end{array}$ & Dirt road & 5720 & 4 & 2.3 \\
\hline 3 & $63: 14: 0803002: 10$ & Windbreak & 7440 & 15 & 11.2 \\
\hline 4 & $63: 14: 0803002: 10$ & Dirt road & 7440 & 4 & 3.0 \\
\hline 5 & $63: 14: 0803002: 3$ & Windbreak & 6300 & 15 & 9.0 \\
\hline 6 & $63: 14: 0803002: 3$ & Dirt road & 6300 & 4 & 2.3 \\
\hline & Total & & & & 36.4 \\
\hline
\end{tabular}

Based on the occupied area calculation, it can be determined that the share of inarable lands as the weeds source on examined land plots is no less than $70 \%$, share of windbreaks and dirt roads - $20-25 \%$, share of applied manure (depending on the rate of use) - no more than $5 \%$, and share of lands around utility poles - $0.013 \%$. Therefore, weeds spots around utility poles play no role in infestation, as, compared to other sources, their share is almost zero [11].

In order to control weeds, the following measure are implemented: preventive (quarantine, organizational) measure and direct control (agrotechnical, biological, chemical, integrated) [12].

In this case, it is most appropriate to use the chemical method of weeds control, which involves using herbicides - chemicals for inhibiting the growth of unwanted plants - that have a number of advantages: high productivity and efficiency (up to 90\%); relatively high economic viability, low costs and high phytotoxicity, possibility of using at different times, selective ability, and an opportunity to choose the most effective chemicals for a specific ecological situation and infestation [13].

Use of systemic non-selective herbicides that affect all plant son the land plot is the most preferred method. 
In order to kill unwanted plants around utility poles, the 'Roundup', 'BP' (glyphosate acid - $360 \mathrm{~g} / \mathrm{l}$ ) herbicides or their alternatives can be used. Such herbicides are used in the afterharvesting estivo-autumnal period, by spraying vegetative annual and perennial grass weeds and dicotyledonous weeds. The chemicals are very strong: when applied to the plant, it moves to the roots, causing the plant to die (up to 95\%).

These chemicals are effective against all weeds, including sow thistle, couch grass, convolvulus, Russian knapweed, dog's tooth grass, etc.

Herbicides can be applied by spraying of ground using the backpack sprayer: the chemicals are distributed evenly over the vegetative weeds and soil. The flow of liquid is 100-200 1/ha. The application rate is 4-6 1/ha. Herbicide is used only once. It is prohibited to apply chemicals in the sanitary zone around fishery waters at a distance of $500 \mathrm{~m}$ away from the flood line given the maximum floodwater stand, but not closer than $2 \mathrm{~km}$ from existing banks.

Plantings should be sprayed with herbicides in the morning or in the evening in calm dry weather, in order to ensure even distribution of the chemicals and prevent it from drifting [14].

According to sanitary requirements, it is necessary that 7 days pass before people can do manual labor on fields treated with herbicides, for machine labor this period is 3 days.

When using herbicides, recommendations and instructions must be followed, alongside with the consumption rate, concentration and method of application. There is also a need to use protective equipment (chemical protective clothing, non-absorbent boots, respirator, goggles, etc.).

The treatment period should be agreed on with land users in accordance with special aspects of the use of land plots, where utility poles are located.

\section{Conclusion}

Survey of land plots with cadastral numbers 63:14:0802002:65; 63:14:0803002:10; 63:14:0802002:66; and 63:14:0803002:3 has shown that weeds spots around utility poles of the 'Maiskaya' $35 \mathrm{~kW}$ power line are of minimum size and have almost no negative impact on agricultural crops cultivation on these land plots, let alone the total area of 4865 ha. Proportion of these spots was less than $0.013 \%$ of all weeds sources, therefore, their impact can be not considered. The main sources of infestation are inarable lands, windbreaks, dirt roads, and fresh manure used as organic fertilizer.

As the most effective method for control of weeds around utility poles, it is preferred to use chemical treatment with non-selective herbicides. Accordingly, the issue of compensation payments should be should be defined by the cost value of chemical treatment of agricultural lands in zones near utility poles, which equals to no more than 1 thousand rubles for the total area.

\section{References}

1. V. Boykov, S. Startsev, A. Protasov, A. Pavlov, E. Nesterov, IOP Conf. Ser.: Earth Environ. 341, 012132 (2019) doi: 10.1088/1755-1315/341/1/012132

2. T. Schohr, E. Gornish, G. Woodmansee, J. Shaw, K. Tate, L. Roche, Environ. Manage. 65, 212-219 (2020) doi: 10.1007/s00267-019-01238-8

3. D. Cook, S. Liu, B. Murphy, W. Lonsdale, Risk Anal., 30, 1303-1314 (2010) doi: 10.1111/j.1539-6924.2010.01439.x

4. A. Poltarykhin, V. Nosov, L. Poletaeva, V. Avdotin, V. Grishin, M. Babakisiyev, J. Environ. Manag. Tour. 10, 508-514 (2019) doi: 10.14505//jemt.v10.3(35).05 
5. T. Ottosen, S. Lommen, C. Skjøth, Comput. Electron. Agric. 157, 232-238, (2019) doi: 10.1016/j.compag.2018.12.031

6. V. Nosov, M. Tindova, K. Zhichkin, M. Mirgorodskaya, IOP Conf. Ser.: Earth Environ. 337, 012014 (2019) doi: 0.1088/1755-1315/337/1/012014

7. A. Artemyeva, A. Dubovskaya, N. Kon'kova, J. Gen. and Breed. 23, 787-794 (2019) doi: $10.18699 / \mathrm{VJ} 19.553$

8. P. Tóth, A. Undas, F. Verstappen, H. Bouwmeester, Front. Plant Sci. 7, 312 (2016) doi: 10.3389/fpls.2016.00312

9. K. Zhichkin, V. Nosov, L. Zhichkina, V. Zhenzebir, O. Sagina, Front. Plant Sci. 421, 022066 (2020) doi:10.1088/1755-1315/421/2/022066

10. K. Zhichkin, V. Nosov, L. Zhichkina, Zh. Dibrova, T. Cherepova, IOP Conf. Ser. Earth Environ. 315, 022023 (2019) DOI:10.1088/1755-1315/315/2/022023

11. S. Engel, S. Pagiola, S. Wunder, Ecol. Econ. 65, 663-674 (2008) doi: 10.1016/j.ecolecon.2008.03.011

12. D. Buhler, Weed Sci. 50, 273-280 (2002) doi: 10.1614/0043-1745

13. B. Strehlow, F. de Mol, B. Gerowitt, Crop Prot. 129, 105011 (2020) doi: 10.1016/j.cropro.2019.105011

14. C. Sattler, H. Kächele, G. Verch, Agr. Ecosyst. Environ. 119, 299-304 (2007) doi: 10.1016/j.agee.2006.07.017 